\title{
Inferences on the source mechanisms of the 1930 Irpinia (Southern Italy) earthquake from simulations of the kinematic rupture process
}

\author{
Antonio Emolo $\left({ }^{1}\right)$, Giovanni Iannaccone $\left({ }^{2}\right)$, Aldo Zollo $\left({ }^{1}\right)$ and Antonella Gorini $\left({ }^{3}\right)$ \\ (1) Dipartimento di Scienze Fisiche, Università degli Studi di Napoli «Federico II», Napoli, Italy \\ ${ }^{2}{ }^{2}$ Istituto Nazionale di Geofisica e Vulcanologia, Osservatorio Vesuviano, Napoli, Italy \\ $\left.{ }^{3}\right)$ Dipartimento della Protezione Civile, Servizio Sismico Nazionale, Roma, Italy
}

\begin{abstract}
We examine here a number of parameters that define the source of the earthquake that occurred on 23rd July 1930 in Southern Italy (in the Irpinia region). Starting from the source models proposed in different studies, we have simulated the acceleration field for each hypothesized model, and compared it with the macroseismic data. We then used the hybrid stochastic-deterministic technique proposed by Zollo et al. (1997) for the simulation of the ground motion associated with the rupture of an extended fault. The accelerations simulated for several sites were associated with the intensities using the empirical relationship proposed by Trifunac and Brady (1975), before being compared with the available data from the macroseismic catalogue. A good reproduction of the macroseismic field is provided by a normal fault striking in Apenninic direction (approximately NW-SE) and dipping $55^{\circ}$ toward the SW.
\end{abstract}

Key words 1930 Irpinia earthquake - ground motion simulation - kinematic source model

\section{Introduction}

At 00:08 UTC on 23rd July 1930, a seismic event completely destroyed several villages (Villanova del Battista, Trevico, Aquilonia and Lacedonia) in the Campania Region of Southern Italy, causing the loss of about 1500 lives. The earthquake was felt over a wide area of about $36000 \mathrm{~km}^{2}$ that covered the Campania, Puglia and Basilicata Regions of Southern Italy (Alfano, 1931). The maximum estimated

Mailing address: Dr. Antonio Emolo, Dipartimento di Scienze Fisiche, Università degli Studi di Napoli «Federico II», Complesso Universitario di Monte S. Angelo, Via Cintia, 80126 Napoli, Italy; e-mail: Antonio.Emolo@na.infn.it intensity for the earthquake was X MCS (Gruppo di Lavoro CPTI, 1999). The damaged area had an elliptical trend that stretched in the Apenninic direction (NW-SE) and showed a weak concavity toward the SW (fig. 1).

In modern seismology, ground motion simulation techniques aim to provide more exact predictions of the ground shaking than those obtained, for example, from conventional seismotectonic analyses and/or from the use of empirical peak attenuation relationships. These can be realised through the calculation of reliable earthquake scenarios. On this basis, the simulation of a seismic wave field has a fundamental role in any predictive estimation of the ground motion parameters that are of engineering interest (ground motion peak parameters, signal spectral content, etc.). Simulation methods are also important in studies of past earthquakes where the instrumental data were poor or completely absent. As shown by the present 


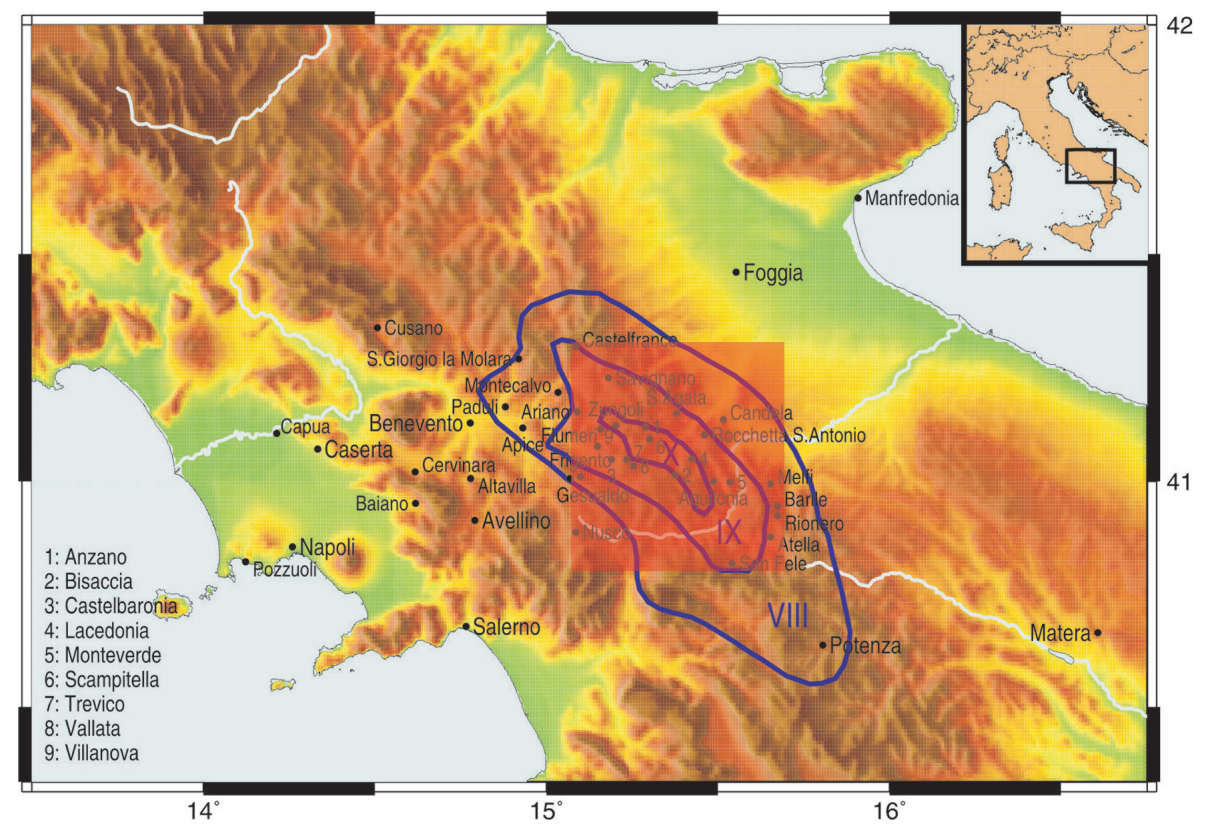

Fig. 1. Isoseismal curves for the 1930 Irpinia earthquake (after Postpischl, 1985). Only the curves corresponding to the degrees VIII, IX and X are reported. The red shaded area corresponds to the region used for this simulation study.

study, simulation of the seismic radiation can be considered a useful approach in the validation of a source model proposed on the basis of seismological, geological and geophysical data.

In the present study, we first reviewed the source parameters of the 1930 Irpinia earthquake, and then we applied a hybrid stochasticdeterministic model of earthquake rupture (Zollo et al., 1997) to assess the acceleration field associated with a number of source models proposed for this earthquake. We also compared the simulated acceleration maps with the macroseismic field to gain insights into the 1930 Irpinia earthquake source parameters. Finally, we propose a new model for this earthquake source.

\section{Epicentre location of the 1930 Irpinia earthquake}

The international seismic bulletins list more than 100 stations that reported $P$ - and/or $S$-wave
Table I. Epicentre locations for the 1930 Irpinia earthquake, as proposed in various studies.

\begin{tabular}{ccc}
\hline \hline \multicolumn{2}{c}{ Epicentre } & Reference \\
Lat. North & Long. East & \\
\hline $41^{\circ} 06^{\prime}$ & $15^{\circ} 24^{\prime}$ & Karnik (1969) \\
$41.04^{\circ}$ & $15.45^{\circ}$ & Postpischl (1985) \\
$41.05^{\circ}$ & $15.42^{\circ}$ & NEIS Catalogue \\
$41.05^{\circ}$ & $15.37^{\circ}$ & Boschi et al. (1995) \\
$41^{\circ} 03^{\prime} 31^{\prime \prime}$ & $15^{\circ} 25^{\prime} 15^{\prime \prime}$ & Oddone (1930) \\
\hline
\end{tabular}

arrival times following the 1930 Irpinia earthquake, which were mostly from Italian and European observatories. The arrival times are given with an accuracy within some seconds, with large inaccuracies that depend on the mechanical clocks used in the seismological observatories at that time. The residuals of the $P$ arrival times reported for some close seismic stations in 


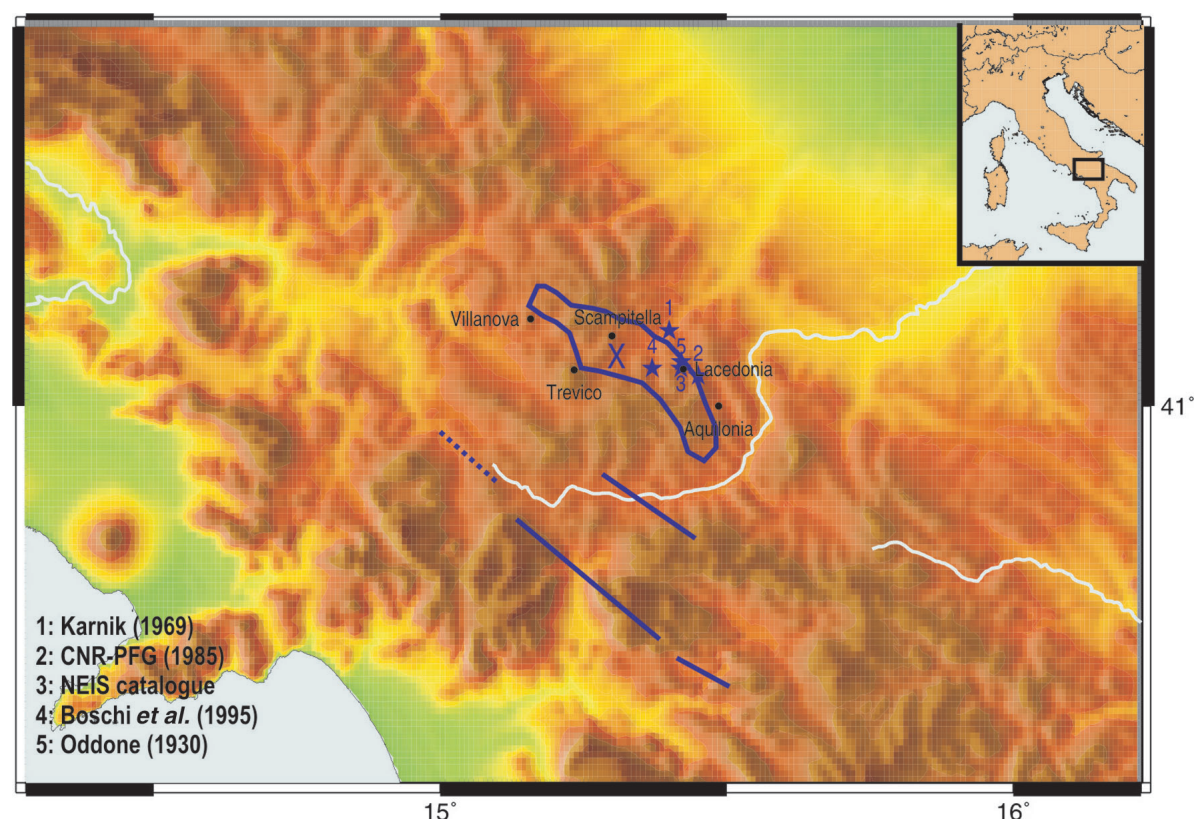

Fig. 2. Epicentre locations for the 1930 Irpinia earthquake proposed by different studies. The isoseismal curve for degree $\mathrm{X}$ is also reported. The blue lines are the fault traces for the 1980 Irpinia earthquake (after Bernard and Zollo, 1989).

the bulletin amount to several tens of seconds. Using these data, various authors have estimated the epicentre location for the 1930 Irpinia earthquake using different methodologies (Oddone, 1930; Karnik, 1969; Postpischl, 1985; NEIS Catalogue; Boschi et al., 1995), as reported in table I and fig. 2. All of the proposed epicentre locations are close to the maximum intensity area. However, and as discussed in the following, the epicentre area and the maximumdamage area should not coincide as the latter is associated with the geometric and dynamic characteristics of the rupturing source as well as the quality of the constructions.

\section{Magnitude and seismic moment}

The seismic intensity data were broadly used in the estimation of the magnitude of the 1930 Irpinia earthquake. Empirical relationships using the maximum intensity in the epi- centre area, $I_{o}$, were applied to obtain a value of the magnitude. For example, Postpischl (1985) assigned a magnitude of 7.0 using an empirical relationship between the maximum intensity and magnitude proposed by Karnik (1969).

Westaway (1992) revised the source parameters for the large historic Italian earthquakes, and determined the relationships among the radii of greater value isoseismal curves and the magnitudes. Applying this to each isoseismal from $I=$ VI to $I=X$, Westaway (1992) deduced a mean value of $M=6.3 \pm 0.2$ for the 1930 Irpinia earthquake. This thus showed that the magnitude scale that was obtained was equivalent to the surface wave magnitude, $M_{S}$.

Using a uniform methodology, Margottini et al. (1993) analysed about 500 bulletins from seismological observatories to estimate the magnitudes of 647 earthquakes that occurred in Italy in the period of 1900-1986. For each earthquake, they used the values of the maximum amplitudes of the recorded ground motion 
Table II. Magnitude and seismic moment for the 1930 Irpinia earthquake, as proposed in various studies (bold type). The values in normal typescript were calculated using the Hanks and Kanamori (1979) relationship: $\log M_{o}=9+1.5 M$.

\begin{tabular}{cccc}
\hline \hline Magnitude & Seismic moment $(\mathrm{Nm})$ & Reference & Data used \\
\hline $\mathbf{6 . 5}$ & $7 \times 10^{18}$ & Martini and Scarpa (1983) & After Karnik (1969) catalogue \\
6.1 & $\mathbf{2} \times \mathbf{1 0}^{\mathbf{1 8}}$ & Jiménez (1988) & Surface waves (spectral analysis) \\
$\mathbf{7 . 0}$ & $3.2 \times 10^{19}$ & Postpischl (1985) & Maximum intensity value \\
$\mathbf{6 . 3} \pm \mathbf{0 . 2}\left(M_{S}\right)$ & $3.5 \times 10^{18}$ & Westaway (1992) & Radii of greatest isoseismal areas \\
$\mathbf{6 . 6} \pm \mathbf{0 . 3}\left(M_{S}\right)$ & $1 \times 10^{19}$ & Margottini et al. (1993) & Amplitudes of surface waves from bulletins \\
$\mathbf{6 . 7}\left(M_{e}\right)$ & $1.1 \times 10^{19}$ & Gasperini et al. (1999) & Epicentre intensity and isoseismal areas \\
\hline
\end{tabular}

according to the characteristics of the recording instruments, and the period that was associated with them. Moreover, in order to account for the effects of crustal structure, they determined a correction factor for each station. In particular, for the 1930 Irpinia earthquake, they used the amplitude of surface waves recorded at 41 seismic stations, thus obtaining a surface wave magnitude $M_{S}=6.6 \pm 0.3$.

Gasperini et al. (1999) proposed a method that used the macroseismic intensity data to assess the location, geometry and magnitude of the source of large historic earthquakes. Based on a dataset of 75 instrumental magnitude values for Italian earthquakes, they calibrated a regression law to obtain the equivalent moment magnitude $M_{e}$ using the epicentre intensity $I_{o}$ and the radii of areas of different intensity levels. The estimated equivalent moment magnitude for the 1930 Irpinia earthquake was $M_{e}=6.7$.

The seismic moment was estimated by Jiménez (1988), who analysed the records of the 1930 Irpinia earthquake obtained at the seismic station of Jena, Germany. This study proposed a method for the retrieval of the focal mechanism parameters and the seismic moment for intermediate sized earthquakes from the surface waves recorded at a single seismic station located at a regional distance. Jiménez (1988) performed a dispersion analysis on the regional Love and Rayleigh wave data in the period range of 30-100 s, and used this to infer the focal mechanism. An analysis of the spectral content of the fundamental modes of the surface waves was then used to calculate the seismic moment. The value obtained for the $1930 \mathrm{Ir}-$ pinia earthquake was $M_{0}=2 \times 10^{18} \mathrm{Nm}$.

Table II summarises the proposed magnitudes and seismic moment values for the 1930 Irpinia earthquake.

\section{The focal mechanism}

There have been several studies of the geometry of the fault-plane of the 1930 Irpinia earthquake that have evaluated the focal mechanisms by $P$-wave polarities or that have applied semi-empirical relationships to macroseismic data. Martini and Scarpa (1983) used the $P$-polarities reported in the seismic bulletins or taken from the original seismograms. They assumed the epicentre given by Karnik (1969), with a depth of $13 \mathrm{~km}$. The solution proposed by Martini and Scarpa (1983) shows a normal fault mechanism with a moderate strike-slip component, with nodal planes oriented approximately in the ESE and WSW directions and dipping $40^{\circ}-60^{\circ}$ (fig. 3).

Jiménez (1988) obtained a fault mechanism with a large strike-slip component with nodal planes oriented in the N-S and E-W directions (fig. 3). Gasperini et al. (1999) analysed macroseismic data and proposed an azimuth of $\mathrm{N} 109^{\circ} \mathrm{W} \pm 11^{\circ}$ for the fault plane, with a fixed mean dip of $45^{\circ}$.

In the present study, independent estimations of focal mechanism were obtained using two different methods on the same dataset as that used by Martini and Scarpa (1983). The da- 
ta used are reported in table III. The first approach was based on a search for the two planes that optimise the polarities distribution on the focal sphere (FPFIT algorithm, Oppenheimer et

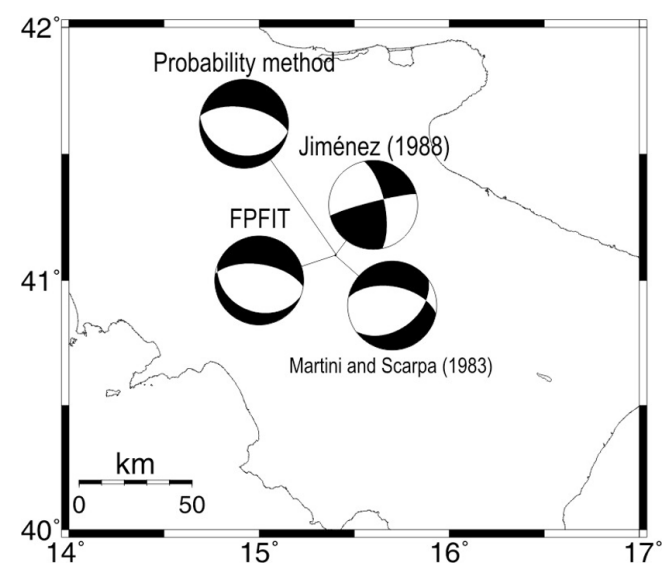

Fig. 3. Fault plane solutions for the 1930 Irpinia earthquake. al., 1988). The second method was that proposed by Zollo and Bernard (1991), based on the probabilistic evaluation of the maximum likelihood model. The fault plane solutions obtained are given in fig. 3 and summarised in table IV. These are similar to those proposed by Martini and Scarpa (1983), and are consistent with the azimuthal value of $109^{\circ}$ for the fault plane given by Gasperini et al. (1999).

\section{Fault dimensions and mean value of slip}

The length, $L$, and the width, $W$, of a fault that has generated an earthquake of magnitude $M$ can be calculated by the relationships provided by Wells and Coppersmith (1994)

$$
\begin{aligned}
& \log L=-2.44+0.59 M \\
& \log W=-1.01+0.32 M
\end{aligned}
$$

where the fault dimensions are expressed in $\mathrm{km}$. Gasperini et al. (1999) inferred a source dimension of $32.6 \times 13.6 \mathrm{~km}^{2}$ using these Wells and

Table III. $P$-polarities used for focal mechanism calculations.

\begin{tabular}{ccccc}
\hline \hline Location & Code & $\begin{array}{c}\text { Epicentre distance } \\
\text { (degrees) }\end{array}$ & $\begin{array}{c}\text { Azimuth } \\
\text { (degrees) }\end{array}$ & Polarity \\
\hline Piacenza (Italy) & PCN & 5.9 & 317 & up \\
Athens (Greece) & ATH & 7.1 & 111 & down \\
Toledo (Spain) & TOL & 14.8 & 273 & down \\
Copenhagen (Denmark) & COP & 14.9 & 354 & up \\
Durham (Great Britain) & DUR & 18.4 & 326 & down \\
Uppsala (Sweden) & UPP & 19.1 & 4 & up \\
Pulkovo (Russia) & PUL & 21.1 & 21 & up \\
Tachkent (Uzbekistan) & TAS & 40.1 & 71 & down \\
\hline
\end{tabular}

Table IV. Source models used for the numerical modelling of the accelerometric field.

\begin{tabular}{cccccccc}
\hline \hline Model & $\begin{array}{c}\text { Length } \\
(\mathrm{km})\end{array}$ & $\begin{array}{c}\text { Width } \\
(\mathrm{km})\end{array}$ & $\begin{array}{c}\text { Max depth } \\
(\mathrm{km})\end{array}$ & Strike & Dip & Rake & Reference \\
\hline A & 14.5 & 9 & 13 & $290^{\circ}$ & $60^{\circ}$ & $-90^{\circ}$ & This study \\
B & 14.5 & 9 & 13 & $100^{\circ}$ & $30^{\circ}$ & $-90^{\circ}$ & This study \\
C & 32 & 14 & 15 & $109^{\circ}$ & $45^{\circ}$ & $-90^{\circ}$ & Gasperini et al. $(1999)$ \\
D & 14.5 & 9 & 13 & $280^{\circ}$ & $55^{\circ}$ & $-60^{\circ}$ & Martini and Scarpa (1983) \\
\hline
\end{tabular}


Coppersmith (1994) relationships. Applying the Wells and Coppersmith (1994) relationships to the magnitude value $M=6.1$ proposed by Jiménez (1988), the fault plane dimensions that are obtained are about $14.5 \times 9 \mathrm{~km}^{2}$.

Once the seismic moment is known, it is possible to estimate the fault dimensions and the mean final slip value for the earthquake under consideration. Using the relationship between seismic moment and fault length for intraplate earthquakes provided by Scholz et al. (1986), we obtained a fault length of about 10$15 \mathrm{~km}$. Moreover, by studying the seismic fracture in conditions of uniform static stress release, Madariaga (1977) established that

$$
\langle D\rangle=\frac{C W D_{s}}{\mu}
$$

where $\langle D\rangle$ is the mean slip value; $W$ is the fault width; $D_{S}$ is the static stress release; $\mu$ is the rigidity; and $C$ is a factor that depends on the geometry of the fractured area and assumes a value of 0.7 for a circular surface and 1.6 for a rectangular fault characterized by a width that is negligible with respect to its length. Combining this relationship with the definition of seismic moment $\left(M_{0}=\mu L W\langle D\rangle\right)$, we obtain a fault width of about $5-10 \mathrm{~km}$. The mean value of the final slip is then between $0.4 \mathrm{~m}$ and $1.3 \mathrm{~m}$.

Table IV summarises the proposed source parameters for the 1930 Irpinia earthquake.

\section{Ground acceleration field simulation}

The goal of our simulation study was to determine the reliabilities of the proposed source models for the 1930 Irpinia earthquake through a comparison of the simulated acceleration field with the macroseismic map. With this in mind, we simulated the ground acceleration field associated with the four source models reported in table IV. For each of the source models considered, we performed simulations of 100 different rupture processes, with each of them based on parameters defined by different positions of the rupture nucleation point (randomly chosen in the lower half of the fault) and by different heterogeneous final slip distributions (calculated according to the $k$-square model proposed by Herrero and Bernard, 1994). For each rupture process, we calculated the ground acceleration at a regular grid of 121 receivers located in an area of $60 \times 60 \mathrm{~km}^{2}$ (the red shaded area in fig. 1). The spacing between adjacent receivers was $5 \mathrm{~km}$. The maximum frequency content of simulated accelerograms was $5 \mathrm{~Hz}$. For each receiver, the ground motion parameters
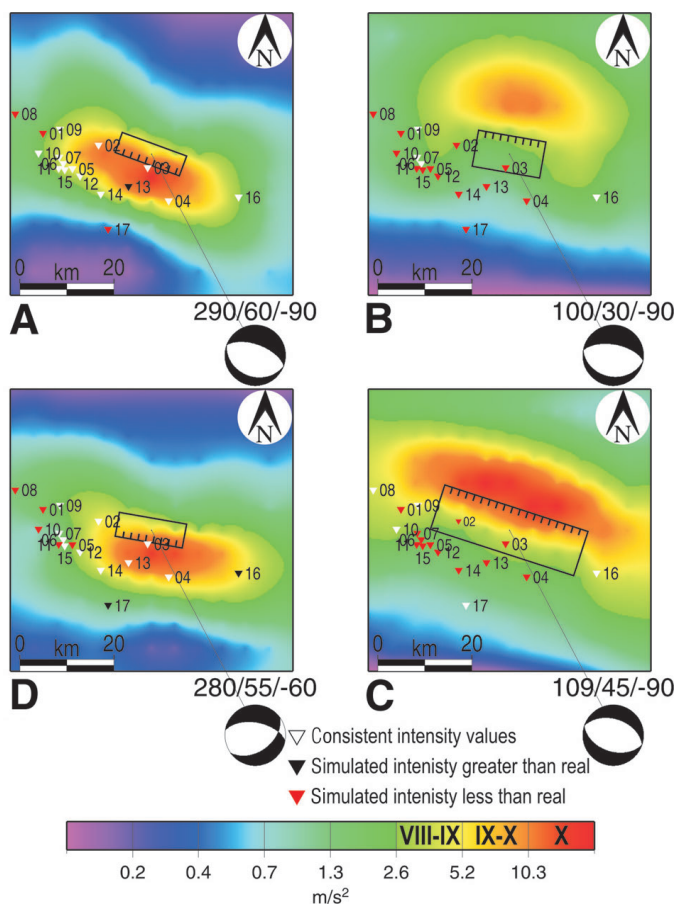

Fig. 4. Peak ground acceleration field simulations for the four source models of table IV. The rectangles represent the surface projection of the fault. The dipping directions of the fault planes and the focal mechanism are also shown. The numbered triangles represent towns (01: Aquilonia; 02: Lacedonia; 03: Scampitella; 04: Villanova; 05: Trevico; 06: Anzano; 07: Ariano Irpino; 08: Bisaccia; 09: Carife; 10: Castel Baronia; 11: Flumeri; 12: Monteverde; 13: Rocchetta S. Antonio; 14: S. Nicola Baronia; 15: S. Sossio Baronia; 16: Vallata; 17: Zungoli; 18: Melfi; 19: Barile; 20: Rionero; 21: San Fele; 22: S. Agata; 23: Atella; 24: Candela; 25: Castelfranco; 26: Frigento; 27: Savignano; 28: Andretta). 
of interest (e.g., the mean values of Peak Ground Acceleration - PGA) were evaluated assuming that the simulated peak accelerations were lognormally distributed. In our modelling, we simulated 100 different rupture processes for each fault model considered, after having verified that a larger number of simulations did not produce substantial differences in the estimation of the mean values of PGA for each receiver.

Figure 4 shows the maps of the PGA (mean values calculated from the 100 simulated rupture processes) for the four source models of table IV. As can be clearly seen, the spatial distribution of the accelerometric field depends on the orientation and dimension of the ruptured surfaces.

The PGAs can then be converted into macroseismic intensities using empirical relationships. In fig. 4 the colour scale was created so that the acceleration ranges for yellow and red correspond to macroseismic intensities in the range IX-X, according to the relationship proposed by Trifunac and Brady (1975)

$$
\log \langle P G A\rangle=0.3 I-1.986 \text {. }
$$

In this way, we can compare qualitatively the isoseismal curves of fig. 1 for the highest intensity degrees with the yellow and red areas of fig. 4 .

We also compared the macroseismic intensity data available from the NT4.1 catalogue $(\mathrm{Ca}-$ massi and Stucchi, 1998) with the theoretical intensity values estimated from the simulated accelerations by the Trifunac and Brady (1975) relationship for several towns. In fig. 4, the white triangles mean that the expected intensity is consistent (within the range of one statistical standard deviation) with the actual intensity data, whereas the black and red triangles mean that the theoretical intensities are greater than and less than the actual data, respectively. Since we do not take in account either site effects or the quality of the constructions, which can strongly influence macroseismic data, we believe that this comparison is not completely satisfactory.

\section{Results: a new source model}

Seismological and macroseismic observations agree on the azimuth of the causative fault of the 1930 Irpinia earthquake, and suggest an Apenninic orientation (approximately ESEWNW) for the fault plane. There are some uncertainties in the definition of the dipping direction of the fault plane (towards the SW or the $\mathrm{NE}$ ). This ambiguity also remains after the analysis of the fault plane solution because we found two possible solutions with the same probability. However, in general the concave shape of the macroseismic field can be associated with a fault plane dipping in the direction of maximum concavity. In the case of the 1930 Irpinia earthquake, the isoseismal curves of fig. 1 show a weak concavity toward the SW, suggesting a plane probably dipping towards the SW. The results from the simulations for source models $\mathrm{B}$ and $\mathrm{C}$ in table IV (fig. 4B,C), which are characterized by fault planes dipping toward the SW, show an acceleration field characterized by a concavity in the fault dipping direction. On this basis, we chose a fault plane oriented in the Apenninic direction and dipping towards the SW.

From fig. 4A,D, it appears that the lateral extension (i.e. in the anti-Apenninic direction) of the peak acceleration field reproduces well the analogue extension of the isoseismal curves (fig. 1). On the other hand, by comparing the results for source models A and B in table IV (fig. $4 \mathrm{~A}, \mathrm{~B})$, we note that when the seismic moment and fractured area are the same, the dip angle is smaller, and the lateral extension of the higher PGA area is larger. In comparison with the macroseismic field, this observation allows us to exclude a sub-horizontal fault plane for the 1930 Irpinia earthquake, and to consider a fault plane with a dip angle of between $40^{\circ}$ and $70^{\circ}$.

The effects of a major strike component in the focal mechanism on the acceleration field can be inferred through comparing the PGA maps for source models $\mathrm{A}$ and $\mathrm{D}$ of table IV (fig. 4A,D); this produces a larger extension in the ESE direction that is not so evident in the macroseismic field (fig. 1).

While we were able to reproduce quite closely the lateral extension of the isoseismal curves corresponding to the highest intensity levels, the longitudinal extension (i.e., in the Apenninic direction) of the highest acceleration areas for source models A, B and D of table IV appears to underestimate the analogous extension of the 
isoseismal curves (i.e., the area corresponding to the intensities of IX-X). As a consequence, we can conclude that the fault dimensions associated with source models A, B and D are too small. On the other hand, in the case of source model C, characterized by the largest fault dimensions among the models considered in this study, we found an acceleration field that greatly overestimates the macroseismic field extension corresponding to the highest intensity levels.

On the basis of the above-mentioned observations, we propose the source model reported in table V for the 1930 Irpinia earthquake. This model is characterized by dimensions which are

Table V. Source model for the 1930 Irpinia earthquake proposed in this study.

\begin{tabular}{cc}
\hline \hline Length $(\mathrm{km})$ & 25 \\
Width $(\mathrm{km})$ & 12 \\
Max depth $(\mathrm{km})$ & 15 \\
Strike & $110^{\circ}$ \\
Dip & $55^{\circ}$ \\
Rake & $-90^{\circ}$ \\
Seismic moment $(\mathrm{Nm})$ & $5.6 \times 10^{18}$ \\
\hline
\end{tabular}

intermediate to those of models A, B and D, and model C, of table IV. The magnitude of about 6.5 , which was evaluated according to the Wells and Coppersmith (1994) relationships, corresponds to a seismic moment of $5.6 \times 10^{18} \mathrm{Nm}$.

To validate our proposed source model, we calculated the mean PGA field associated with 100 possible rupture processes occurring on this fault. We then converted the PGA estimated for the 28 towns in the area under consideration into macroseismic intensities through the Trifunac and Brady (1975) relationship, and searched for the fault position able to minimise the differences between the estimated and observed macroseismic data available from the NT4.1 catalogue (Camassi and Stucchi, 1998). The final results are shown in fig. 5. The synthetic acceleration field reproduces the characteristics of the macroseismic field well. Moreover, the fault moves about $10 \mathrm{~km}$ in a SW direction as compared to the proposed epicentre locations shown in fig. 2. As can be seen, the fault position does not coincide with the maximum area where it was felt.

The «Database of Potential Sources for Earthquakes Larger than M 5.5 in Italy» (Valensise and Pantosti, 2001) adopts the source parameters and location proposed by Gasperini et
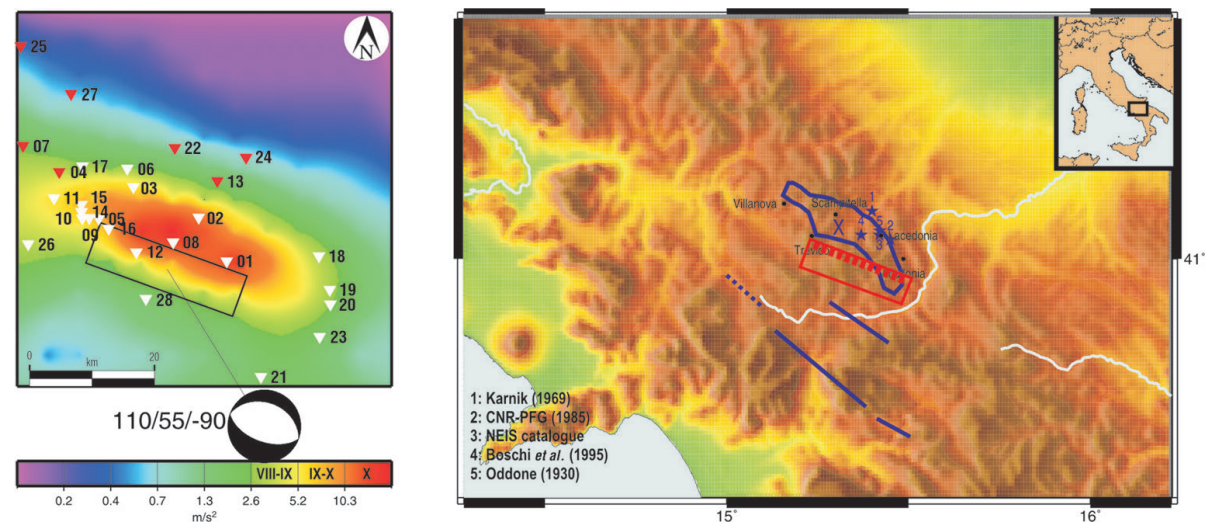

Fig. 5. Final sketch of the 1930 Irpinia earthquake. Left: map of the simulated peak ground acceleration field. The rectangle represents the surface projection of the fault. The dipping direction of the fault plane and the focal mechanism are also shown. The triangles represent towns (see legend to fig. 4). The white triangles represent towns for which the actual intensity data are consistent with that simulated; the red triangles represent towns for which the actual intensity data are greater than simulated. Right: same map as fig. 2 but with the fault represented (red rectangle). 
al. (1999). These are based only on the analysis of macroseismic intensity data. However, as pointed out by Basili and Burrato (2001), the 1930 Irpinia earthquake did not generate clear surface faulting and this makes it difficult to determine the exact position of the causative fault.

In conclusion, we propose that the fault associated with the 1930 Irpinia earthquake is located in the central part of the Southern Apennine chain, and dips in a SW direction, similar to the eastern segment associated with the 1980 Irpinia earthquake.

\section{Acknowledgements}

We thank L. Improta for helpful discussions. We would also like to thank G. Cultrera, an anonymous reviewer and $\mathrm{M}$. Cocco for their constructive comments.

\section{Appendix}

This appendix is devoted to the description of the method used in this study to simulate the seismic ground motion associated with an extended fault, as proposed by Zollo et al. (1997).

Radiation from a seismic source $\Sigma$ can be calculated from the representation theorem. The ground displacement as a function of time $t$ at the point $\vec{r}$ for the wave $c$ is given by (Aki and Richards, 1980)

$$
\vec{u}_{c}(\vec{r}, t)=\iint_{\Sigma} \vec{G}\left(\vec{r}, \vec{r}_{0}, t\right) * \Delta u\left(\vec{r}_{0}, t\right) d \Sigma\left(\vec{r}_{0}\right)
$$

where $\Delta u$ is the slip function at the point $\vec{r}_{0}$ on the fault, and $\vec{G}$ is the Green's function for a point dislocation source.

The exact calculation of $\vec{G}$ is a very difficult problem that leads to complicated numerical methods. Bernard and Madariaga (1984) and Spudich and Frazer (1984) independently proposed that it is possible to use only the far-field Green's function in eq. (A.1). This approximation is valid when the wavelengths under consideration are much shorter than the smallest distance to the fault. The range of validity of this approximation does not depend on the dimensions of the fault. Farra et al. (1986) provided numerical justification for the use of an asymptotic Green's function at high frequencies also for wavelengths shorter than the distance to the fault. In other words, they showed that the asymptotic method yields good results for wavelengths of the order of the distance to the fault, and that this deteriorates relatively quickly once the wavelengths become longer. The general form of the Green's function in far-field approximations was given by (Farra et al., 1986)

$$
\vec{G}^{F F, c}(\vec{r}, \overrightarrow{0}, t)=\frac{\mu_{0}}{4 \pi \rho_{0} c_{0}^{3}} \operatorname{Re}\left\{\sqrt{\frac{\rho_{0} c_{0}}{\rho c J}} \vec{F}_{c} \prod \dot{\Delta}\left[t-T_{c}\left(\vec{r}_{0}\right)\right]\right\}
$$

where $\mu$ and $\rho$ are the rigidity and the density, respectively; $c$ is either the $P$ - or $S$-wave velocity, according to the type of wave under consideration (the suffix 0 means «evaluated at the source»); $J$ is the geometric spreading factor; $\vec{F}_{c}$ is a vector radiation pattern which depends on the take-off angle of the ray at the source and on the geometric properties of the dislocation source; $\Pi$ contains the product of all of the complex reflection and transmission coefficients at the different interfaces encountered by the ray on its trajectory; $\Delta(t)=\delta(t)-i / \pi t$; and $T_{c}$ is the travel time. Complex $\Pi$ occurs when a ray is reflected at supercritical angles, whereas $J \leq 0$ if the rays have touched a caustic. Thus, eq. (A.2) is very general, and allows the calculation of all of the geometric rays. The most important advantage of using the far-field Green's function is that the numerical evaluation of eq. (A.1) becomes very fast. Each Green's function is convolved with the Azimi's attenuation function (Aki and Richards, 1980) based on parameters defined by a constant quality factor $Q_{c}$ in order to account for the Earth anelasticity. 
The slip function in eq. (A.1) can be approximated by a ramp function

$$
\Delta u\left(\vec{r}_{0}, t\right)= \begin{cases}0 & \text { for } t<T_{R}\left(\vec{r}_{0}\right) \\ \frac{D\left(\vec{r}_{0}\right)}{\tau\left(\vec{r}_{0}\right)}\left[t-T_{R}\left(\vec{r}_{0}\right)\right] & \text { for } T_{R}\left(\vec{r}_{0}\right)<t<T_{R}\left(\vec{r}_{0}\right)+\tau\left(\vec{r}_{0}\right) \\ D\left(\vec{r}_{0}\right) & \text { for } t>T_{R}\left(\vec{r}_{0}\right)+\tau\left(\vec{r}_{0}\right)\end{cases}
$$

where $D\left(\vec{r}_{0}\right), \tau\left(\vec{r}_{0}\right)$ and $T_{R}\left(\vec{r}_{0}\right)$ represent the final slip, the rise time and the rupture time associated with the fault element with a position of $\vec{r}_{0}$, respectively.

In the near-source distance range (i.e., when the distance between the source and the receivers is comparable to the dimensions of the fault), the details of the rupture process may largely influence the high frequency seismic radiation. On the other hand, the heterogeneous final slip and rupture velocity distributions of the fault are rather complex, as can be seen from near-source strong motion data (Hartzell and Heaton, 1983; Heaton, 1990). This complexity can be related to the variable rock strength and/or applied stress field along the faulting surface. Thus, to sum up, in the near-source range, the high frequency seismic radiation is controlled by the complexity and heterogeneity of the rupture processes that dominate the character of the signals when the site effects can be considered as being weak or negligible.

Under a constant rupture velocity hypothesis, the $\omega$-square behaviour of the seismic ground motion spectra (Aki, 1967) can be related to self-similar slip and stress-drop distributions over the fault, that follow a negative power law as a function of the radial wave number $k$ (Andrews, 1981; Frankel, 1991; Herrero and Bernard, 1994). We adopted the $k$-square model by Herrero and Bernard (1994) to obtain a heterogeneous final slip distribution on the fault plane from the two-dimensional inverse Fourier transform of the complex function

$$
\tilde{D}\left(k_{x}, k_{y}\right)=C \frac{1}{1+\left(\frac{k}{k_{c}}\right)^{2}} e^{i \varphi\left(k_{x}, k_{y}\right)}
$$

where $k$ is the radial wave-number. The cut-off wave-number, $k_{c}$, corresponds to the minimum fault dimension (Herrero and Bernard, 1994) and represents the characteristic dimension of the fault. When $k>k_{c}$, the dislocation is supposed to be incoherent on the fault plane and, in this case, the phase $\varphi$ in eq. (A.4) is chosen randomly. The slip distribution is then tapered by a two-dimensional cosine-taper filter to avoid unrealistically sharp slip transitions at fault edges. Finally, the constant $C$ in eq. (A.4) is evaluated by normalizing the slip distribution, to obtain an a priori value of seismic moment.

If a constant rupture velocity is used, the far-field seismic radiation is dominated by the slip heterogeneity instead of the irregularities in the rupture velocity distribution. This approximation may not be valid for highly discontinuous fracture phenomena, but it is reasonable when the rupture velocity varies smoothly along the fault.

The rise time value in eq. (A.3) is generally chosen as the cut-off frequency of the low-pass filter that is applied to the synthetic seismograms. In this case, the onset of slip appears to be instantaneous with the passage of the rupture front. This choice maximizes the expected amplitude of the ground motion in the far-field approximation.

The representation integral in eq. (A.1) is evaluated numerically by dividing the fault into discrete sub-faults, and then summing up their contributions. A fine fault grid is needed to calculate the representation integral up to high frequencies, to avoid undesired numerical effects due to the fault dividing (e.g., spatial aliasing). Zollo et al. (1997) suggested characteristic sub-fault dimensions of about $20-30 \mathrm{~m}$. 
This simulation method can be used to obtain predictive estimates of strong ground motion parameters of engineering interest (peak parameters and spectral ordinates) in seismically active areas. Paleoseismic evidence of the occurrence of repeated rupture episodes along the same fault (or fault system) suggests that some characteristics, like fault geometry, source mechanism, and average slip, depend on the direction and intensity of the regional stress field, and it is reasonable to consider these constant on a large time scale. This concept is supported by several paleoseismic studies performed on active faults in different tectonic environments (e.g., Pantosti and Valensise, 1990; Pantosti et al., 1993; Meghraoui et al., 2000). However, numerical simulations of fracture development suggest that the fracture process may not repeat the same style of nucleation, propagation and arrest in successive rupture events along a given fault (e.g., Rice, 1993; Nielsen et al., 1995, 2000). On this basis, a massive calculation of synthetic seismograms produced by a large number of possible rupture processes occurring on the same a priori known fault is performed. Assuming a constant rupture velocity, the history of each rupture is built from a heterogeneous final slip distribution and a rupture nucleation point randomly chosen over the fault plane. Considering that the source effects are dominant at nearsource distances, the variability of the synthetic strong motion records should account for the a priori unknown rupture complexity. The range of expected variations of typical strong-motion parameters for a given seismogenetic fault (or fault system) can therefore be estimated by statistical analysis. For these reasons, Zollo et al. (1997) defined their simulation method as a hybrid stochastic-deterministic technique.

This simulation approach was used by Zollo et al. (1997) to estimate the strong ground motion parameters for the Friuli earthquake (1976, $M=6.5)$, and by Zollo et al. (1999) to calculate the ground motion scenario associated with a hypothetical earthquake occurring on the Ibleo-Maltese fault system in South-Eastern Sicily. It has also been recently validated by Emolo and Zollo (2001), who simulated the two main shocks of the Umbria-Marche seismic sequence (26th September, 1997; the $M_{W}=$ $=5.5$ and $M_{W}=6.0$ events).

\section{REFERENCES}

AKI, K. (1967): Scaling law of seismic spectra, J. Geophys. Res., 72, 1217-1231.

AKI, K. and P.G. RICHARDS (1980): Quantitative Seismology, Theory and Methods (W.H. Freeman and Co., San Francisco, USA), vols. 1 and 2, pp. 932.

Alfano, G.B. (1931): Il terremoto irpino del 23 luglio 1930, Pubbl. Osservatorio di Pompei, 1031, 3-57.

Andrews, D.J. (1981): A stochastic fault model, 2. Timeindependent case, J. Geophys. Res., 86, 10821-10834.

Basili, R. and P. Burrato (2001): Operating manual, Ann. Geophysics, 44 (suppl. to no. 4), 835-888.

Bernard, P. and R. MAdariaga (1984): A new asymptotic method for the modelling of near-field accelerograms, Bull. Seismol. Soc. Am., 74, 539-555.

BernARD, P. and A. Zollo (1989): The Irpinia (Italy) 1980 earthquake: detailed analysis of a complex normal fault, J. Geophys. Res., 94, 1631-1648.

Boschi, E., G. Ferrari, P. Gasperini, E. Guidoboni, G. SMriglio and G. VALENSISE (1995): Catalogo dei Forti Terremoti in Italia dal 461 a.C. al 1980 (ING, RomaSGA, Bologna), vol. 1, pp. 974.

Camassi, R. and M. Stucchi (1998): NT4.1, un Catalogo Parametrico di Terremoti di Area Italiana al di Sopra della Soglia del Danno (on line: http://emidius.itim.mi.cnr.it/ NT/home.html).

Emolo, A. and A. Zollo (2001): Accelerometric radiation simulation for the September 26, 1997 Umbria-Marche (Central Italy) main shocks, Ann. Geofis., 44 (3), 605617.

FARRA, V., P. BERNARD and R. MADARIAGA (1986): Fast near source evaluation of strong ground motion for complex source models, in Earthquake Source Mech., Am. Geophys. Union Monogr. 37, 121-130.

FRANKEL, A. (1991): High-frequency spectral falloff of earthquakes, fractal dimension of complex rupture, b value, and the scaling of strength on fault, J. Geophys. Res., 96, 6291-6302.

Gasperini, P., F. Bernardini, G. VAlensise and E. Boschi (1999): Defining seismogenic sources from historical earthquake felt report, Bull. Seismol. Soc. Am., 89, 94110.

GruPPO DI LAVORO CPTI (1999): Catalogo Parametrico dei Terremoti Italiani (ING, GNDT, SGA, SSN, Bologna), pp. 92.

HANKS, T.C. and H. KANAMORI (1979): A moment-magnitude scale, J. Gephys. Res., 84, 2348-2352.

HARTZELL, S. and T.H. HEATON (1983): Inversion of strong ground motion and teleseismic waveforms data for the fault rupture history of the 1979 Imperial Valley, California, earthquake, Bull. Seismol. Soc. Am., 73, 1553-1583.

HEATON, T.H. (1990): Evidence for and implications of selfhealing pulses of slip in earthquake rupture, Phys. Earth Planet. Int., 64, 1-20.

HERrERo, A. and P. BERNARD (1994): A kinematic self-sim- 
ilar rupture process for earthquakes, Bull. Seismol. Soc. Am., 84, 1216-1229.

JIMÉNEZ, E. (1988): Etude des mécanismes au foyer à partir d'une station unique: application aux domaines EuroMéditerranéen et Sud-Ouest Pacifique, Ph.D. Thesis (Université L. Pasteur, Stasbourg).

KARNIK, V. (1969): Seismicity of the European Area (Kluwer, Dordrecht).

MADARIAGA, R. (1977): Implications of stress-drop models of earthquakes for inversion of stress-drop from seismic observations, Pure Appl. Geophys., 115, 301-315.

Margottini, C., N.A. Ambraseys and V. Petrini (1993): La magnitudo dei terremoti Italiani del XX secolo, Rapporto Tecnico ENEA.

MARTINI, M. and R. SCARPA (1983): Earthquakes in Italy in the last century, in Earthquakes: Observation, Theory and Interpretation, edited by $\mathrm{H}$. KANAMORI and E. BoschI, Scuola Italiana di Fisica «E. Fermi», 85th Course, Bologna, 479-492.

Meghraoui, M., T. Camelbeck, K. Vanneste, M. BronDEEL and D. JongMANS (2000): Active faulting and paleoseismology along the Bree Fault, lower Rhine Graben, Belgium, J. Geophys. Res., 105, 13809-13841.

NEIS Catalogue, National Earthquake Information Service of USGS (on line: http://neic.usgs.gov/neis).

Nielsen, S.B., L. KNOPOFF and A. TARANTOla (1995): Model of earthquake recurrence: role of elastic wave radiation, relaxation of friction, and inhomogeneity, $J$. Geophys. Res., 100, 12423-12430.

Nielsen, S.B., J.M. CARLSON and K.B. Olsen (2000): Influence of friction and fault geometry on earthquake rupture, J. Geophys. Res., 105, 6069-6088.

ODDONE, E (1930): Studio sul terremoto avvenuto il 23 Luglio 1930 nell'Irpinia, Relazione a S.E. il Ministro dell'Agricoltura e Foreste, in La Meteorologia Pratica (Regio Ufficio Centrale di Meteorologia e Geofisica).

OPPENHEIMER, D.H., P.A. REASENBERG and R.W. SiMPSON (1988): Fault plane solution for the 1984 Morgan Hill, California, earthquake sequence: evidence for the state of stress on the Calaveras Fault, J. Geophys. Res., 93, 9007-9026.

PANTOSTI, D. and G. VALENSISE (1990): Faulting mechanism and complexity of the November 23,1980, CampaniaLucania earthquake, inferred from surface observation, J. Geophys. Res., 95, 15319-15341.
Pantosti, D., D. Schwartz and G. Valensise (1993): Paleoseismicity along the 1980 surface rupture of the Irpinia Fault: implications for earthquake recurrence in the Southern Apennines, Italy, J. Geophys. Res., 98 6561-6577.

PostPISCHL, D. (Editor) (1985): Atlas of isoseismal maps of Italian earthquakes, Quad. Ric. Sci., 114 (2A), pp. 164

RICE, J.R. (1993): Spatio-temporal complexity of slip on fault, J. Geophys. Res., 98, 9885-9907.

Scholz, C.H., C. Aviles and S. Wesnousky (1986): Scaling differences between large intraplate and interplate earthquakes, Bull. Seismol. Soc. Am., 76, 65-70.

SPudich, P. and L.N. Frazer (1984): Use of ray theory to calculate high-frequency radiation from earthquake sources having spatially variable rupture velocity and stress drop, Bull. Seismol. Soc. Am., 74, 2061-2082.

TRIFUNAC, M.D. and A.G. BRADY (1975): On the correlation of seismic intensity data in California and Western Nevada, Bull. Seismol. Soc. Am., 65, 139-162.

VAlensise, G. and D. Pantosti (Editors) (2001): Database of potential sources for earthquakes larger than M 5.5 in Italy, Ann. Geofis., 44 (suppl. to n. 4) pp. 180 (with CD-ROM).

Wells, D.L. and K.J. Coppersmith (1994): New empirical relationships among magnitude, rupture length, rupture width, rupture area, and surface displacement, Bull. Seismol. Soc. Am., 84, 974-1002.

WESTAWAY, R. (1992): Seismic moment summation for historical earthquakes in Italy: tectonic implications, $J$. Geophys. Res., 97, 415-437.

Zollo, A. and P. Bernard (1991): Fault mechanism from near source data: joint inversion of $S$ polarizations and $P$ polarities, Geophys. J. Int., 104, 441-451.

Zollo, A., A. Bobbio, A. Emolo, A. Herrero and G. De NATALE (1997): Modelling of the ground acceleration in the near source range: the case of 1976 Friuli earthquake $(M=6.5)$, Northern Italy, J. Seismol., 1, 305-319.

Zollo, A., A. Emolo, A. Herrero and L. Improta (1999): High frequency strong motion modelling in the Catania area associated with the Ibleo-Maltese fault system, $J$. Seismol., 3, 279-288.

(received November 21, 2003

accepted November 8, 2004) 